\title{
Assessment of the Effectiveness of Toxoplasma Surface Antigen Grade I for Diagnosis of Human Toxoplasma gondii
}

\author{
Abdelrahman Ramzy Elmowafy ${ }^{1 *} \mathrm{MSc}$, Adham Gamal Sadek ${ }^{1} \mathrm{PhD}$, Alaa Abdelaziz Samn ${ }^{1} \mathrm{PhD}$, Hanan Taher \\ $\mathrm{Hamza}^{2 \cdot 3} \mathrm{PhD}$ and Ibrahim Rabae ${ }^{4} \mathrm{MD}$
}

\author{
*Corresponding Author \\ Abdelrahman R Elmowafy \\ abdorme81.ae@gmail.com \\ Received for publication October 27, \\ 2020; Accepted January 15, 2021; \\ Published online February 1, 2021 \\ Copyright 2020 The Authors published \\ by Al-Azhar University, Faculty of \\ Medicine, Cairo, Egypt. All rights \\ reserved. This an open-access article \\ distributed under the legal terms, where \\ it is permissible to download and share \\ the work provided it is properly cited. \\ The work cannot be changed in any \\ way or used commercially. \\ doi: 10.21608/aimj.2021.42859.1321 \\ ${ }^{1}$ Department of Zoology, Faculty of \\ Science, Al-Azhar University, Cairo, \\ Egypt. \\ ${ }^{2}$ Department of Zoology, Faculty of \\ Science (for girls), Al-Azhar \\ University, Cairo, Egypt. ${ }^{3}$ Department \\ of Biology, College of Science, \\ Jouf University, P.O. Box 2014, \\ Sakaka, Saudi Arabia ${ }^{4}$ Department of \\ Parasitology, Theodor Bilharz \\ Research Institute, Giza, Egypt.
}

\begin{abstract}
Background: Toxoplasmosis represents a neglected equatorial poverty disorder triggered by an intracellular mandatory protozoan parasite, known as Toxoplasma gondii.

Aim of the work: The purpose of this study was to assess the Effectiveness of Toxoplasma Surface Antigen Grade I for diagnosis of human Toxoplasma gondii in Egypt by Sandwich ELISA Technique.

Subjects and Methods: This study was conducted on 94 individuals, divided into 3 categories, category I: Toxoplasma gondii, category II: Other parasites, it encompassed 10 infected patients that have $E$. histolytica and 14 infected with G. lamblia, and category III: Healthy control group.

Results: The cutoff value was 0.233 when detecting Toxoplasma (SAG1). The serum findings appear positive in 43 cases ( 86 percent) of category I, whilst 7 cases (14 percent) appear negative. In category II (patient with different parasites): 10 positive cases of Entamoeba histolytica have been confirmed, while the other 14 cases were positive with $G$. lamblia. All healthy control cases (category III) were negative. The sensitivity was $86 \%$ However; the specificity was observed at $81.81 \%$.

Conclusion: From the obtained results, we can conclude that: to evaluate the different immunodiagnostic antigens detection assays, choice, and purification of the suitable antigen, accompanied by the manufacture and purification of its particular antibodies, are mandatory. The employment of rabbit anti-Toxoplasma gondii IgG polyclonal antibodies in sandwich ELISA techniques for the identification of SAG1 in human serum provides a sensitive and specific tool for immunodiagnosis in human toxoplasmosis.
\end{abstract}

Keywords: Toxoplasmosis; Diagnosis; Sandwich ELISA; Surface antigen

Disclosure: The authors have no financial interest to declare in relation to the content of this article. The Article

Processing Charge was paid for by the authors.

Authorship: All authors have a substantial contribution to the article

\section{INTRODUCTION}

Toxoplasma gondii (T.gondii), known as the intracellular parasitic coccidia that infects both animals and human beings. ${ }^{1}$ It was mentioned in 1908 in desert rodent Ctenodactylus gundii by Manceaux and Nicolle, and in laboratory rabbit by Splendore. Unlike Plasmodium, that has been documented around 30 years earlier, it was indeed a comparatively benign parasite. $^{2}$ It , is an apicomplexan species among zoonotic parasites with species as final and intermediate hosts as well, although vertebrates with warm blood are intermediate hosts, even bird species. The disease occurs when tissue cysts or mature oocysts are swallowed, shed, and sporulated in the ecosystem by the final hosts. T. gondii is global in distribution and is one of the most predominant human parasites. ${ }^{3}$ Toxoplasmosis differs from asymptomatic disorder, a self-limiting disorder to a deadly illness, viewed in a weakened patient with historical factors that affect the end-result for infection. ${ }^{4} T$. gondii surface is considered the first part to reach host cells and the parasite's surface antigen is considered to be the main target of the study..$^{5}$ There are various serological techniques for detecting humoral antibodies, including Sabin-Feldman dye method, latex agglutination method, indirect fluorescent antibody test (IFAT), indirect hemagglutination method, direct agglutination method and enzyme-linked immune sorbent assay (ELISA). ${ }^{6}$ Serum antigen detection assay is typically performed by ELISA sandwich. ${ }^{7}$ It 
has more than 1000 proteins and glycoproteins which form a wide range of antigens. ${ }^{8}$ These antigens are complex and originate from the different structures of the parasite which include: surface (membrane) antigens, stage-specific antigens (specific to the Toxoplasma gondii tachyzoite, bradyzoite, and oocysts/sporozoite stage $)^{9}$ and circulating antigens which are excretion, secretion and lyses products of the parasite that circulate in the blood during early acute infection. ${ }^{10}$ In the superfamily of surface antigens, five proteins are found in $T$. gondii, including p23, p35, SAG1, SAG2, and SAG3 ${ }^{5}$ This research aimed to evaluate the efficacy of Toxoplasma Surface Antigen Grade I (SAG1) for diagnosis of human toxoplasmosis in Egypt by Sandwich ELISA Technique.

\section{PATIENTS AND METHODS}

Patients

Collection of samples: Serum samples were collected from Egyptian patients during the period from $8 /$ 2016 to 7 / 2017 from Cairo lab, which is a private lab after ethical approval. The practical part of this work was performed in the Parasitology Department at Theodor Bilharz Research Institute (TBRI).

Animals and Parasites

Animals: White male rabbit, about 1.5 kilograms (kg) in weight, at the age of two months, bought from rabbit research unit (RRU), Faculty of Agriculture, University of Cairo. Before the beginning of the experimental studies, It was examined and tested for being free of parasitic infections, and utilized in the manufacturing of antibodies. ${ }^{11}$ It had been maintained for 4 weeks (experimental duration) in line with normal laboratory condition at $21^{\circ} \mathrm{C}, 16$ percent moisture, filtered drinking water with additional salts, $1 \mathrm{gm} / 5$ liters, and vitamin $1 \mathrm{ml} / 10$ liters. The nutrition includes 15 percent proteins, 3 percent fats, and 22 percent fibers, bought from RRU. ${ }^{12}$ Studies on animals had been performed in compliance with standards that are internationally acceptable. ${ }^{13}$

Parasites: Toxoplasma tachyzoites were extracted from the peritoneal fluid of mice and were transferred in phosphate buffer saline (PBS) to our laboratory in TBRI. ${ }^{14}$

Study population: This research was carried out on 94 individuals; the participants grouping was performed as follows:

Category I: 50 Toxoplasma gondii-positive patients based on the existence of antibodies in their serum.

Category II: 24 patients carrying other parasites ( $G$. lamblia \& E. histolytica).

Category III: 20 seemingly stable toxoplasmosis-free individuals and other parasitic diseases acted like negative control.

The sera from the 3 groups were isolated and kept at $-20^{\circ} \mathrm{C}$ until tested.

Preparation of Toxoplasma antigen: Toxoplasma tachyzoites underwent 3 freezing and thawing periods. Preparation of Toxoplasma antigen was done according to Brooks et al. ${ }^{15}$ and Parvar et al. ${ }^{16}$

Purification of the target antigen

Purification of the target antigen by DEAE-Sephadex A-50 ion-exchange chromatography.
Purification by chromatography with gel filtration by Sephadex G-50.

Electrophoresis of sodium dodecyl sulfatepolyacrylamide gel (SDS-PAGE): Migration of proteins in electrophoresis depends primarily on the size, charge, and shape of the molecules. ${ }^{17}$

Assessment of Toxoplasma antigen reactivity via ELISA Assay (indirect): This technique, with several changes of the initial Engvall and Perlmanm methods, was used. ${ }^{18}$

Rabbit immunization for producing polyclonal antibodies: Before injection, blood samples were obtained from the healthy rabbit, tested with ELISA for T.gondii Abs. as mentioned by Gubadia and Fagbemi. ${ }^{19}$ Rabbit anti - T.gondii serum was obtained by immunizing of rabbit with Toxoplasma antigen, during the entire process of immunization, $1 \mathrm{mg}$ of Toxoplasma antigen was given to the rabbit. Rabbit received priming dosage intramuscular injection (i.m.) at four sites, $1 \mathrm{mg}$ Toxoplasma antigen in $700 \mu$ combined with $700 \mu$ complete Freund's adjuvant 1:1 (CFA), (Sigma). ${ }^{16}$ Three enhancement doses had been administered, each with $0.5 \mathrm{mg}$ of antigen solubilized around the same level of incomplete Freund's adjuvant (IFA), (Sigma). ${ }^{17}$ First enhancing had been 2 wks. after the priming dose. ${ }^{17}$ Doses had been administered during weekly periods after the boost, according to Fagbemi and Guobadia. ${ }^{20}$ Blood samples had been obtained before any dose of immunization was injected to measure the antibody (Ab) by indirect ELISA. Rabbit's serum which contains anti-Toxoplasma polyclonal antibodies (pAb) IgG was separated and maintained at $-20^{\circ} \mathrm{C}$. Purification of anti-Toxoplasma rabbit serum: Purification by $50 \%$ ammonium sulfate precipitation: In solutions, proteins create bonds of hydrogen with water via its revealed polar, ionic groups. ${ }^{18}$ Such groups are competing with proteins to bind with water when a high concentration of extremely-loaded ions, for example, ammonium or sulfate is placed. ${ }^{18}$ This eliminates the molecules of water from proteins, reduces their solubilization, leading to precipitation according to Nowotny. ${ }^{21}$

Purification by $7 \%$ Caprylic acid method: In moderately acidic environments, except IgG, the addition of short-chain fatty acids like caprylic acid to the serum precipitates many serum proteins according to Mckinney and Parkinson. ${ }^{22}$

Conjugation of polyclonal antibodies using the periodate process with (HRP) Horseradish peroxidase: Most widely used method of labeling IgG antibody molecules with HRP is the Periodate technique that exploits glycoprotein nature for the enzyme. ${ }^{20}$ To create an aldehyde group that could interact against an amino group of $\mathrm{IgG}$ molecules, saccharide residue of an enzyme were oxidized with sodium periodate, and Schiff bases produced are decreased providing stable high molecular weight conjugate according to Tijssen $\&$ Kurstak. $^{23}$

Detection of SAG1 by Sandwich ELISA in the serum: Microtiter plate (Dynex) was used to detect SAG 1 in serum, the ELISA microplate reader (BioRad) was used to read the plates at $492 \mathrm{~nm}$.

\section{RESULTS}

Estimation of the total protein content of Toxoplasma (SAG 1): 
Total protein content for (SAG1) was $2.1 \mathrm{mg} / \mathrm{ml}$ as assessed by the Bradford method.

Purification with DEAE Sephadex A-50 ionexchange chromatography of the target antigen.

Figure 1 shows the $\mathrm{OD}_{280}$ profile of antigen fractions obtained with DEAE-Sephadex A-50 ion-exchange chromatography following purification. On fraction number 5 , the eluted antigen was described by a single peak with a maximum OD value identical for 1.7 (represented the fraction with the highest protein content).Figure 1

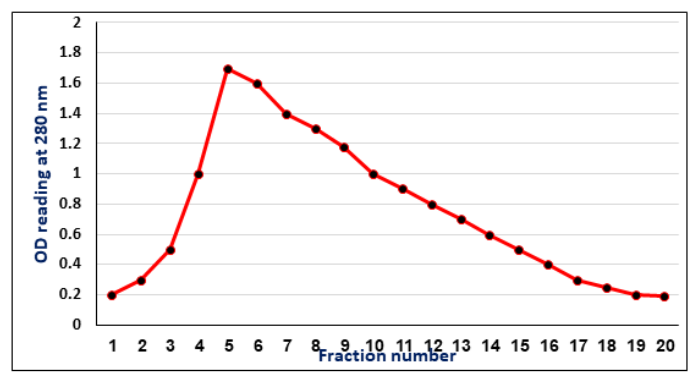

Fig 1: Elute profile for chromatography of Toxoplasma surface antigen grade I (SAG1) on Sephadex A-50 column

Purification by Sephadex G-50 column gel filtration chromatography

Partially purified antigen eluted by DEAE Sephadex A-50 ion-exchange chromatography with highest protein content $(5 \& 6 \& 7 \& 8 \& 9)$ was further purified by DEAE Sephadex G-50 gel filtration column chromatography and the fraction number 9 represents the fraction with the highest protein content at OD $280 \mathrm{~nm}$ (1.4) (Figure 2).

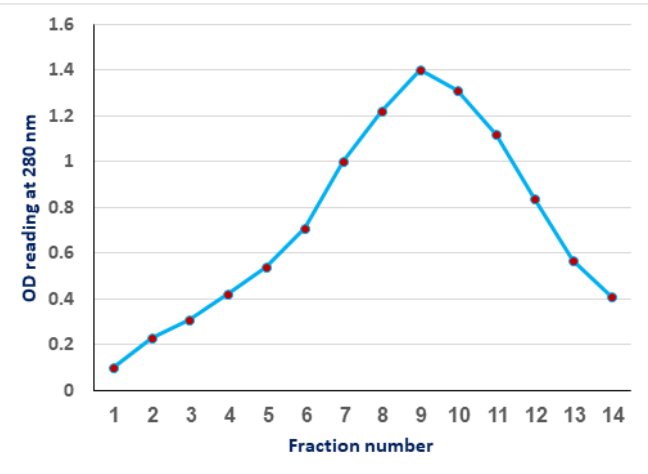

Fig 2: Elute profile for chromatography of Toxoplasma surface antigen grade I (SAG1) on Sephadex G-50 column

Electrophoresis of sodium dodecyl sulfatepolyacrylamide gel (SDS-PAGE):

Characterization of Toxoplasma antigen had been resolved by SDS PAGE (12.5\%) underneath decreasing circumstance, colored by Coomassie blue. Bands of proteins were noticed at 25 and $30 \mathrm{KDa}$ (Figure 3).
Fig 3: $12.5 \%$ SDS PAGE for SAG1 pre and

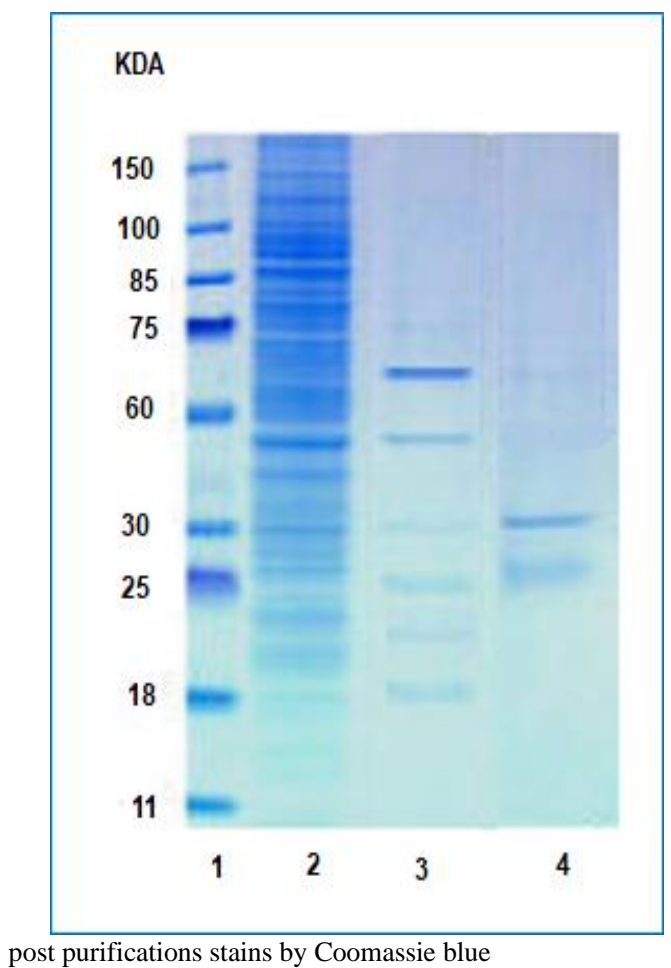

Assessment of Toxoplasma surface antigen grade I reactivity by indirect ELISA is presented in Table 1.

\begin{tabular}{|l|c|}
\hline \multicolumn{1}{|l|}{ Serum Sample } & $\begin{array}{c}\text { OD Reading On } 492 \mathrm{~nm} \\
(\mathrm{M} \pm \mathrm{SD})\end{array}$ \\
\hline T. gondii & $1.360 \pm 0.401$ \\
\hline E. histolytica & $0.203 \pm 0.122$ \\
\hline G. lamblia & $0.121 \pm 0.101$ \\
\hline Healthy Control & $0.105 \pm 0.051$ \\
\hline
\end{tabular}

$\mathrm{OD}=$ optical density $; \mathrm{M}=$ mean and $\mathrm{SD}=$ standard deviation

Table 1: Reactivity of purified target antigen by indirect ELISA

Detection of pAb titers and testing the reactivity of anti- Toxoplasma $\mathrm{IgG}$ polyclonal antibodies against Toxoplasma SAG1

Rising levels of antibodies began one-week post first booster dosage. 3 days post 3rd booster dosage, the immune serum grants high titer within OD of 1.1 at 1/250 dilution against Toxoplasma antigen. Figure 4. 


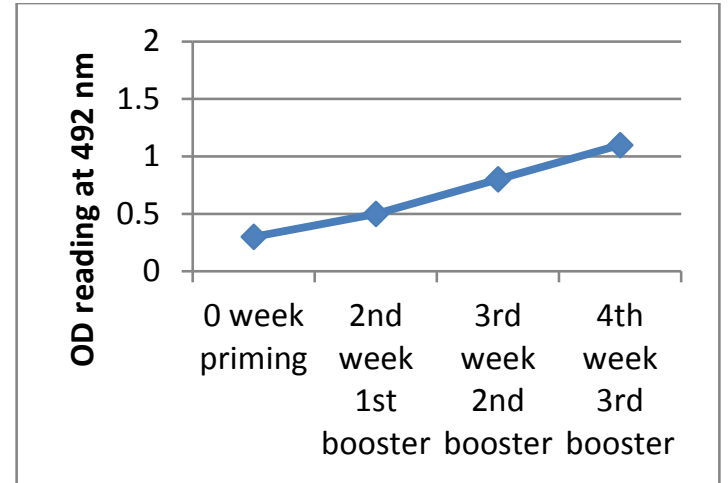

Fig 4: Reactivity by ELISA (indirect) of immunized rabbit anti-Toxoplasma IgG (pAb) against Toxoplasma SAG1

Determination of protein content after rabbit antiToxoplasma polyclonal antibody purification:

Total raw rabbit serum protein content containing anti-Toxoplasma antibodies was $8.0 \mathrm{mg} / \mathrm{ml}$. Protein content was $5.0 \mathrm{mg} / \mathrm{ml}$ with 50 percent ammonium sulfate precipitation process, but content decreased to $2.7 \mathrm{mg} / \mathrm{ml}$ following a 7 percent caprylic acid precipitation procedure. Figure 5.

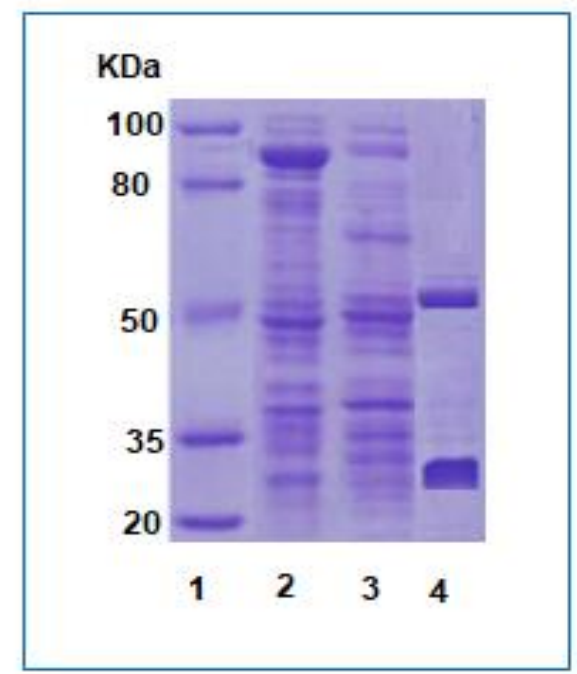

Fig 5: 12.5 percent SDS PAGE for anti-Toxoplasma IgG $(\mathrm{pAb})$ pre and post purification (colored by Coomassie blue).

Anti-IgG pAb reactivity against Toxoplasma (SAG1) and other parasite antigens:

The reactivity of $1 / 500$ diluted anti-Toxoplasma antibodies in PBS / $\mathrm{T}$ resulted in high Toxoplasma antigen reactivity. For Toxoplasma, the OD reading at $492 \mathrm{~nm}$ became 1.4 comparisons with 0.194 and 0.205 concerning E. Histiolytica, As for G. lamblia. Conjugation of polyclonal antibodies of purified rabbit anti-Toxoplasma IgG with (HRP)

The content of the protein had been $2.7 \mathrm{mg} / \mathrm{ml}$ of polyclonal antibodies conjugated with HRP.

Determination of optimal coating concentrations of
anti-Toxoplasma $\operatorname{IgG}$ polyclonal antibodies in sandwich ELISA:

Optimal coating concentrations for anti-Toxoplasma IgG pAb display within highest OD reading at 492 $\mathrm{nm}$ against different concentrations of Toxoplasma antigen after the subtraction of background was found to be $20 \mu \mathrm{g} / \mathrm{ml}$ in sandwich ELISA the OD value $=1.9$. Figure 6

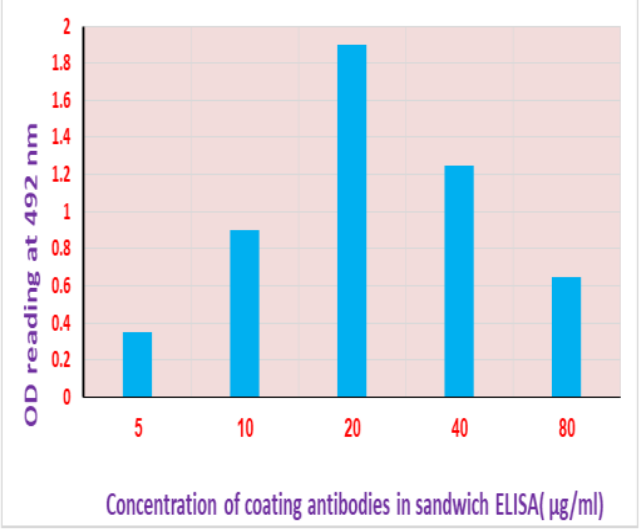

Fig 6: Determining the optimal concentration of the purified anti-Toxoplasma IgG polyclonal antibodies as a coating layer in ELISA sandwich

Determination of optimum rabbit anti-Toxoplasma IgG HRP conjugate concentration as antigen detecting antibodies by sandwich ELISA

The optimum concentration of the conjugate was 40 $\mu \mathrm{g} / \mathrm{ml}$ which gave the highest OD $(1.627 \pm 0.102)$ reading against Toxoplasma SAG1 after subtraction of the background and was chosen as a working dilution for subsequent assays. Figure 7.

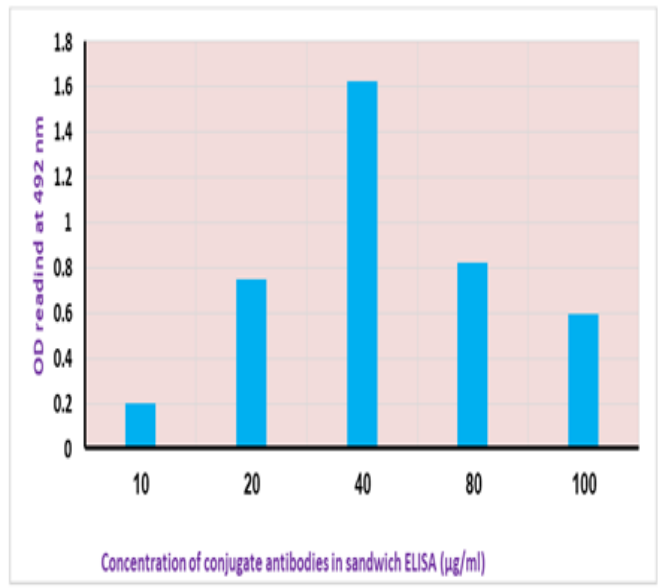

Fig 7: Determination of the optimum concentration of conjugate antibodies in sandwich ELISA

Detection of Toxoplasma surface antigen grade I (SAG1) in the serum samples by sandwich ELISA. Table 2 


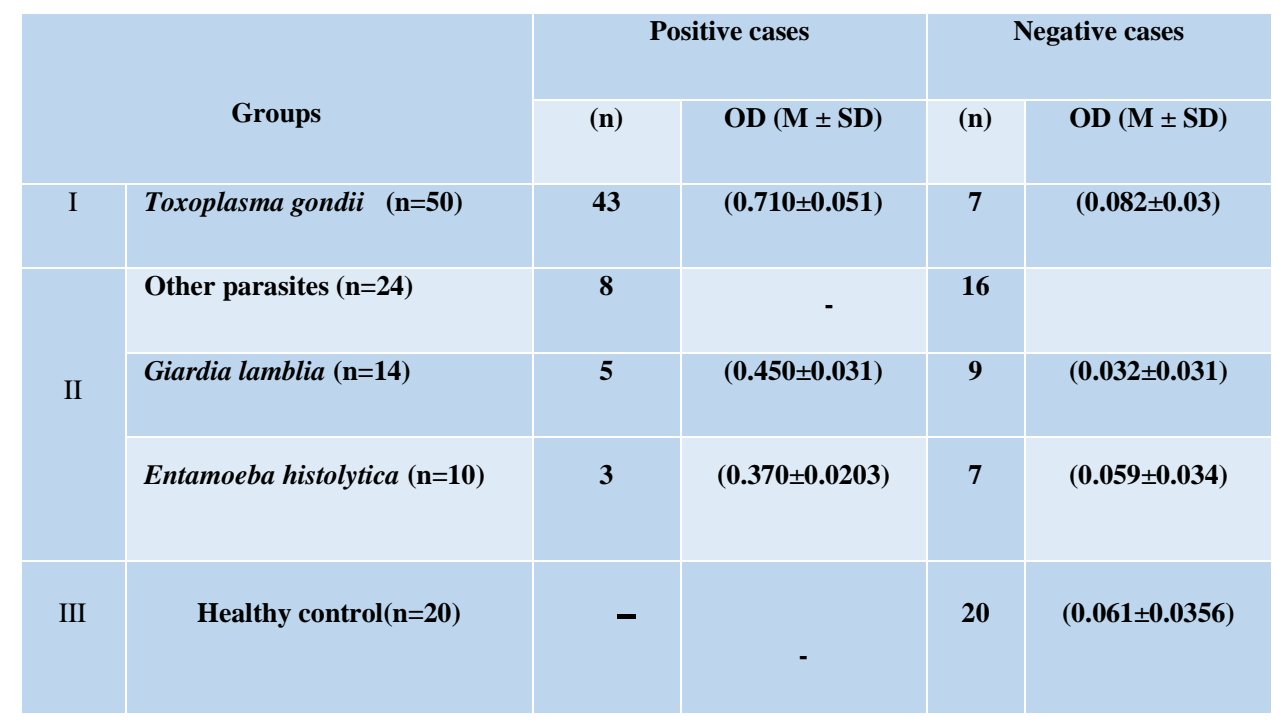

$\mathrm{OD}=$ optical density, $\mathrm{M}=$ mean, $\mathrm{SD}=$ standard deviation and $\mathrm{n}=$ number

Table 2: Detection of Toxoplasma surface antigen grade I (SAG1) in the serum samples using sandwich ELISA in the different studied groups

The level of Toxoplasma surface antigen grade I (SAG1) was calculated at $492 \mathrm{~nm}$ OD reading. The positivity cut-off point and the line of demarcation between negative and positive data had to be calculated first. When detecting Toxoplasma (SAG1) the cut-off values were 0.233 . In serum, findings had been positive in 43 individuals ( 86 percent) of group I, whilst 7 individuals had been negative (14 percent). The sensitivity was $86 \%$ but, the specificity was found to be $81.81 \%$.

\section{DISCUSSION}

Our goal for this research was intended to test the efficacy of Toxoplasma Surface Antigen Grade I (SAG 1) for the diagnosis of human Toxoplasma gondii in Egypt by Sandwich ELISA Technique. The surface antigen grade I (SAG1) was used in the present study because it is found in both tachyzoites and bradyzoites. In this current work, Toxoplasma gondii RH strain tachyzoites were used for the preparation of SAG1. Purification of SAG1 was performed with ion-exchange chromatography by Sephadex A-50, total protein content for raw antigen was $2.1 \mathrm{mg} / \mathrm{ml}$, compared to $1.7 \mathrm{mg} / \mathrm{ml}$ post purification by DEAE-Sephadex A-50 ion-exchange chromatography, and it had been $1.3 \mathrm{mg} / \mathrm{ml}$ next purification by DEAE-Sephadex G-50. Toxoplasma surface antigen grade I (SAG1) has been utilized with incomplete and complete Freund's adjuvants with rabbit immunization for the preparation of polyclonal anti-toxoplasma antibodies. Lipman et al. ${ }^{24}$ reported that choosing to prepare polyclonal antibodies to have many advantages over monoclonal antibodies. Compared with the cost of monoclonal antibody technology, polyclonal antibodies are cheap to manufacture. Besides, it is possible to generate significant amounts of polyclonal antibodies from the serum of immunized animals. Finally, pAb with high affinity can be isolated only 2-3 months after the initial immunization. In the present work purification of the prepared polyclonal antibodies (pAb) was carried out by two different methods including 50\% ammonium sulfate precipitation technique then followed by $7 \%$ caprylic acid purification technique. The use of these purification methods proved a highly purified IgG fraction as demonstrated by Mckinney \& Parkinson. ${ }^{22}$ Detection of Toxoplasma SAG1 by sandwich ELISA in serum samples revealed that 43 out of 50 Toxoplasma cases (group I) were positive, while 7 cases were negative. In group II (patients with other parasitic infection) 8 patients gave positive results, no positive results were obtained in the healthy control group (group III).

\section{CONCLUSION}

Finally, from the obtained results, we can conclude that: To evaluate the different immunodiagnostic antigens detection assays selection of the proper antigen and its purification, followed by the production of its specific antibodies and purification were mandatory. The employment of rabbit antiToxoplasma gondii IgG-polyclonal antibodies in ELISA sandwich techniques for detecting SAG1 in human serum provides a sensitive and specific tool for immune-diagnosis of human toxoplasmosis.

\section{REFERENCES}

1.Tenter AM, Heckeroth AR and Weiss LM. Toxoplasma gondii: from animals to humans. Int J Parasitol. 2000; 30 (12-13): 12171258.

2.Morrissette NS and Ajioka JW. The early years of Toxoplasma research: What's past is prologue. International Journal for Parasitology 2009; 39 (8): 865-869.

3.Aguirre AA, Longcore T, Barbieri M, et al. The one health approach to toxoplasmosis: epidemiology, control, and prevention strategies. Ecohealth 2019; 16 (2): 378-390. 
4.Thomas PA and Pelloux H. Toxoplasmosis, congenital, and in immunocompromised patients: A parallel study. Parasitol Today 1993; 9 (2): 6163.

5.Handman E, Goding JW and Remington JS. Detection and characterization of membrane antigens of Toxoplasma gondii. J. Immunol.1980; 124 (6):2578-2583.

6.Montoya JG. Laboratory diagnosis of Toxoplasma gondii infection and toxoplasmosis. J. Infect. Dis. 2002; 15; 185 (1): 73-82.

7.Aly I, Zalat R, El Aswad BE, et al. Novel nanomagnetic beads based-latex agglutination assay for rapid diagnosis of human schistosomiasis haematobium. International Scholarly and Scientific Research \& Innovation, 2013; 7(12):641 $-647$.

8.Pfefferkorn ER: Cell biology of Toxoplasma gondii. In Modern Parasite Biology: Cellular, immunological and molecular aspects, edited by Wyler DJ $3^{\text {rd }}$ edition, Freeman and Company, New York: 1990; 26-50.

9.Contini C, Saraceni S, Misurati E, et al. A multiplex PCR assay for molecular recognition of T. gondii stage-specific genes. J. Eukaryot. Microbiol. Supp (1): 2001; 191-192.

10. Hughes HPA and Van knapen F. Characterization of a secretory antigen from Toxoplasma gondii and its role circulating antigen production. Int. J. Parasitol. 1982; 12 (5): 433 - 437.

11.Abdel-Rahman EH and Abdel-Megeed KN. Fasciola gigantica: immunization of rabbits with proteins isolated from coproantigen. J. Egypt. Soc. Parasitol. 2004; 34 (2): 631 - 642.

12. El Deeb S, Aly I, Mahna N, et al. Purification and Characterization of Echinococcus granulosus Cathepsin-B Protein and Evaluation of its Role as a Diagnostic Marker. Global Veterinaria 2017; 18 (2): 137-145.

13.Naderi MM, Sarvari A, Milanifar A, et al. Regulations and ethical considerations in animal experiments. Avicenna J Med Biotechnol. 2012; 4 (3): $114-120$

14.Wastling JM and Mattsson JG. Detection of Toxoplasma gondii. Methods Mol. Biol. 2003; 216 (6): 289-297.

15.Brooks RG, Sharma SD and Remington JS. Detection of Toxoplasma gondii antigen by a dotimmunobinding technique. J. Clin. Microbiol. 1985; 21(1):113-116.

16.Parvar FF, Keshavarz H and Shojaee S. Detection of Toxoplasma gondii antigens in sera and urine of experimentally infected mice by capture ELISA. Iran. J. Parasitol. 2008; 3(1):1-5.

17.Laemmli UK. Cleavage of structural proteins during the assembly of the head of bacteriophage T4. Nature (London) 1970; 15; 227(5259):680685.

18.Engvall E and Perlmann P. Enzyme-linked immunosorbent assay. Quantitative assay of $\operatorname{IgG} J$. Immunol. 1971; 8(9): 871-874.

19.Guobadia EE and Fagbemi BO. The isolation of $F$. gigantica specific antigens and their use in the serodiagnosis of fascioliasis in sheep by the detection of circulating antigens. Vet. Parasitol. 1997; 68(3): 269-282.
20.Fagbemi BO and Guobadia EE. Immunodiagnosis of fascioliasis in ruminants using a $28-\mathrm{kDa}$ cysteine protease of $F$. gigantica adult worm. Vet. Parasitol. 1995; 57(4): 309-318.

21.Nowotny A: Basic Exercises in Immunochemistry. Springer Verlag, $2^{\text {nd }}$ edition, Berlin Heidelberg. New York. 1979; 7-20.

22.Mckinney MM and Parkinson AA. Simple, nonchromatographic procedure to purify immunoglobulins from serum and ascitic fluid. $J$. Immunol. Meth. 1987; 96(2): 271-278.

23.Tijssen $\mathrm{P}$ and Kurstak E. Highly efficient and simple methods for the preparation of peroxidase and active peroxidase-antibody conjugate for enzyme immunoassays. Anal. Biochem. 1984; 136(2): 451- 457.

24.Lipman NS, Jackson LR, Trudel LJ, et al. Monoclonal versus polyclonal antibodies: distinguishing, characteristics, applications, and information resources. ILAR J. 2005; 46(3): 258268 